\title{
Canopy Position Affects Pigment Expression and Accumulation of Flavedo Carbohydrates of 'Nules Clementine' Mandarin Fruit, Thereby Affecting Rind Condition
}

\author{
Paul J.R. Cronje ${ }^{2}$ and Graham H. Barry ${ }^{1}$ \\ Citrus Research International, Department of Horticultural Science, Stellenbosch University, Western \\ Cape, 7602, Stellenbosch, South Africa

\begin{abstract}
Marius Huysamer South Africa
\end{abstract} \\ Department of Horticultural Science, Stellenbosch University, Western Cape, 7602, Stellenbosch,
}

\begin{abstract}
AdDITIONAL INDEX WORDS. photosynthetically active radiation, rind pigments, fruit photosynthesis, rind breakdown
ABstract. Because photosynthesis provides the required carbohydrates for fruit development and respiration releases the stored energy from these carbon compounds, interalia during postharvest storage, it is therefore important that fruit tissues have an adequate carbohydrate concentration at the start of the postharvest period to ensure optimal storage life. In addition to photosynthate supply from leaves, the chlorophyll-containing flavedo of citrus (Citrus sp.) fruit (outer, colored part of the rind) has the ability to fix $\mathrm{CO}_{2}$ through its own photosynthetic system. In this experiment, spanning three seasons, the three main sugars (sucrose, glucose, and fructose) were quantified in the flavedo of 'Nules Clementine' mandarin (Citrus reticulata) fruit during Stages II and III of fruit development. Flavedo was sampled from fruit borne on the inside (low light intensity) or outside (high light intensity) of the tree's canopy. In one season, the photosynthetic and respiration rates of fruit borne in the two canopy positions were measured pre- and post-color break (March and April, respectively). Sucrose concentration increased constantly from initial sampling in February until harvest (May), whereas glucose and fructose concentrations increased significantly only during the last month of fruit development. The flavedo of inside fruit, developing under low-light conditions, was less well colored (higher hue angle) and had a lower sugar concentration compared with outside fruit developing under conditions of high light levels. This response could be attributed to the higher pigment concentration leading to a higher photosynthetic rate as well as greater sink strength of the outside fruit. The inside fruit had an increased susceptibility to the progressive postharvest physiological disorder, rind breakdown. The lower carbohydrate and pigment concentrations of the rind from fruit borne inside the canopy compared with those from the outside of the canopy could be indicative of a weaker rind condition at the time of harvest.
\end{abstract}

The citrus fruit is botanically classified as a hesperidium berry and has a leathery rind that is important from a horticultural perspective in that it is essentially this structure that determines the fruit's commercial value in the fresh fruit market. It is the lack of any lesions, physical or physiological, as well as adequate color development of the flavedo that are the main attributes, which determine a citrus fruit's external quality. It is also this structure, comprising a vascular system, pigmentcontaining plastids, and stomata, which allows the rind to conduct leaf-associated physiological processes. However, it is probably the complexity of the rind structure and physiology that allows for the numerous disorders to develop pre- and postharvest [i.e., creasing, chilling injury $(\mathrm{CI})$, rind pitting, rind staining, rind breakdown, and peteca spot] that reduce the value of citrus fruit worldwide (Cronje, 2007; El-Otmani et al., 2011).

Citrus fruit have a relatively constant supply of leafproduced photosynthates, except when inhibited by low winter

Received for publication 7 Sept. 2012. Accepted for publication 18 Mar. 2013. We thank Elizabeth Rohwer for assistance with the carbohydrate analysis and Gerhard Jacobs for critical review of the manuscript.

${ }^{1}$ Present address: XLnT Citrus, P.O. Box 5349, Western Cape 7135, South Africa.

${ }^{2}$ Corresponding author. E-mail: paulcronje@sun.ac.za. temperatures (Syvertsen and Lloyd, 1994). In contrast to the citrus fruit pulp, carbohydrate supply to the flavedo and albedo not only occurs through the phloem from leaves (Koch, 1984; Purvis and Yelenosky, 1983), but also from the fixation of $\mathrm{CO}_{2}$ in the flavedo itself through photosynthesis and refixation of fruit respiratory $\mathrm{CO}_{2}$ (Bean and Todd, 1960; Huang et al., 1992). The carbohydrate concentration in the rind (flavedo and albedo) and pulp increases steadily during fruit maturation (Koch and Avigne, 1990; Tadeo et al., 1987) but differs in specific carbohydrates. For example, the carbohydrates of 'Satsuma' mandarin (Citrus unshiu) rind (30\% sucrose, 32\% fructose, $38 \%$ glucose) differ from the pulp (65\% sucrose, $20 \%$ fructose, $14 \%$ glucose) (Komatsu et al., 1999, 2002). It is thought that the carbohydrate concentration of the citrus flavedo affects rind condition in the postharvest environment and its sensitivity to the development of physiological disorders such as CI (Holland et al., 2002; Purvis and Grierson, 1982; Purvis and Rice, 1983) in addition to being responsible for the chloroplast-chromoplast conversion during rind color development (Barry and le Roux, 2010; Huff, 1984).

Photosynthesis of orange (Citrus sinensis) and lemon (Citrus limon) fruit, which takes place in the chlorophyll-containing flavedo, was initially considered of minor importance in fruit development and only compensating for respiration, even at 
maximum photosynthesis rates (Bean and Todd, 1960; Bean et al., 1963; Todd et al., 1961). However, by measuring photosynthesis of fruit on the tree, Moreshet and Green (1980) considered the flavedo as self-sustaining in carbohydrate synthesis. Further supporting data were presented pertaining to extensive $\mathrm{CO}_{2}$ fixation occurring from flowering until fruit maturation and even during the high respiration rates of early fruit development (Huang et al., 1992; Vu et al., 1985; Yen and Koch, 1990). Rind carbohydrate supply from leaf photosynthesis was calculated by Koch (1984) to be $35 \%$ of the total, concurring with Purvis and Yelenosky (1983) who showed that defoliation and girdling reduced rind carbohydrate concentration. Yen and Koch (1990) reported that grapefruit (Citrus paradisi) leaf photosynthates are supplied primarily to the pulp, whereas the rind photosynthates remain mostly in the flavedo and to a lesser extent in the albedo with an insignificant amount translocated to the juice vesicles. Evidence therefore suggests that flavedo photosynthesis contributes to rind carbohydrate concentration, therefore enabling the rind to act as neither a classical carbohydrate source (for the pulp) nor a sink (from the leaves) during rind development (Goldschmidt and Koch, 1996; Huang et al., 1992; Yen and Koch, 1990).

Canopy microclimate is recognized for its importance in fruit production, and positive relationships exist among light levels [photosynthetically active radiation $(P A R)$ ], temperature, and fruit carbohydrate accumulation (Barry et al., 2000; Morales et al., 2000; Reitz and Sites, 1948; Sites and Reitz, 1949). Comparable physiological responses to temperature and light levels were reported in citrus fruit and citrus leaf photosynthesis by Moreshet and Green (1980). However, as opposed to Bean and Todd (1960), Moreshet and Green (1980) did not find a light saturation point for fruit photosynthesis, although they recorded such a value for the 'Valencia' orange leaves used in the study. Moreshet and Green (1980) concluded that the $\mathrm{CO}_{2}$ uptake of the flavedo is not only dependent on light levels, but also fruit size (relating to stomatal density), chlorophyll concentration as well as the epidermal conductance, which has an important regulatory function. The $\mathrm{CO}_{2}$ assimilation rate of 'Valencia' orange fruit was calculated as being $50 \%$ to $75 \%$ lower than that of leaves. This could be attributed to the $30 \%$ to $40 \%$ lower stomatal frequency and responsiveness in fruit flavedo (Blanke, 1996; Blanke and Lenz, 1989). In addition, the plugging of stomata by the developing wax layer on the fruit surface (Turrell and Klotz, 1940) and the reduction of chlorophyll concentration toward maturity (Bean et al., 1963; Bean and Todd, 1960; Moreshet and Green, 1980) would also result in a lower fruit photosynthetic rate.

Refixation of respiratory $\mathrm{CO}_{2}$ can contribute significantly to the fruit carbohydrate balance, and Huang et al. (1992) calculated grapefruit flavedo to refix $30 \%$ to $100 \%$ of the respiratory $\mathrm{CO}_{2}$ during fruit development. This refixation of $\mathrm{CO}_{2}$ also avoids excessive water loss and prevents anoxic conditions by avoidance of excessive internal $\mathrm{CO}_{2}$ levels (Aschan and Pfanz, 2003).

In view of this, the first objective of this study was to determine the pattern of change of the sucrose, fructose, and glucose concentrations in the flavedo of 'Nules Clementine' mandarin fruit from after physiological fruit drop until harvest (Stages II and III). The second objective was to determine if flavedo carbohydrate concentration is influenced by canopy position, viz. outside the tree canopy with full sunlight or inside the canopy (less than $80 \%$ sunlight). The third objective was to determine whether photosynthetic rate differed for fruit developing under these two light conditions before and after color break of the rind. The fourth objective was to determine if these canopy positions influence the susceptibility to the physiological disorder called rind breakdown (Cronje et al., 2011). It is hypothesized that the flavedo of fruit borne inside the canopy (low PAR exposure) has a lower carbohydrate concentration in comparison with flavedo from fruit borne outside the canopy (high $P A R$ exposure) and that a lower photosynthetic rate of inside fruit is at least partly responsible for this difference in carbohydrate concentration and possibly for an increased susceptibility to rind breakdown development.

\section{Materials and Methods}

Sites AND Plant MATERIAL. This experiment was conducted in an orchard of 'Nules Clementine' mandarin budded on Carrizo citrange (Poncirus trifoliata $\times C$. sinensis) rootstock. In the 2004, 2005, and 2007 seasons, fruit were sampled from the orchard at the University of Stellenbosch experimental farm, Western Cape Province, South Africa, whereas in 2006, no data were collected as a result of low fruit set. These orchards were planted with a north to south row orientation in 1991 at spacing of $4.5 \times 2.5 \mathrm{~m}$.

Treatments, FRUit SAMPling, AND DATA COLlection. For the preharvest fruit sampling, eight adjacent single-tree replicates $(\mathrm{n}=8)$ were used, from which 25 inside and 25 outside fruit were sampled monthly, starting after physiological fruit drop and coinciding with Stages II and III of fruit development (January to May) (Bain, 1958). The treatments were two canopy positions, viz. outside (exposed fruit receiving greater than $80 \%$ of full sunlight) or inside (fruit out of direct sunlight receiving $20 \%$ to $30 \%$ of full sunlight). In both cases, fruit were sampled from a height of 1 to $2 \mathrm{~m}$ from the ground level.

Fruit weight was measured (EK-300i; A\&D Co., Tokyo, Japan) followed by rind color of each fruit using a chromameter (NR 4000; Minolta, Osaka, Japan) before removing the flavedo with a lemon zester. The flavedo that was removed of the 25 fruit from a treatment position, (i.e., inside or outside) was pooled for each of the eight replicate trees $(n=8)$ for the monthly sampling date to ensure that there was enough material for analysis; i.e., chlorophyll and carotenoid as well as carbohydrate concentrations. The flavedo was frozen in liquid nitrogen whereafter it was freeze-dried (Freezemobile 25ES; VirTis Co., Gardiner, NY) and stored at $-80^{\circ} \mathrm{C}$.

Fruit were harvested at commercial maturity in May from the trees according to the two sampling positions and placed into two separated wooden bins to determine rind breakdown incidence during postharvest storage. The fruit were transported to a commercial packhouse where they were drenched (1000 mg $\cdot \mathrm{L}^{-1}$ thiabendazole, $500 \mathrm{mg} \cdot \mathrm{L}^{-1}$ guazatine, $250 \mathrm{mg} \cdot \mathrm{L}^{-1}$ 2.4-D sodium salt, and $1000 \mathrm{mg} \cdot \mathrm{L}^{-1}$ dimethyldidecyl ammonium chloride) and degreened ( $3 \mathrm{~d}$ at $3 \mu \mathrm{L} \cdot \mathrm{L}^{-1}$ ethylene, greater than $90 \%$ relative humidity, and 20 to $22{ }^{\circ} \mathrm{C}$ ) before receiving all standard commercial packhouse treatments [500 $\mathrm{mg} \cdot \mathrm{L}^{-1}$ thiabendazole, $500 \mathrm{mg} \cdot \mathrm{L}^{-1}$ imazalil, $125 \mathrm{mg} \cdot \mathrm{L}^{-1}$ 2,4-dichlorophenoxyacetic acid, and polyethylene citrus wax application (Citrushine ${ }^{\circledR}$; Citrosol, Johannesburg, South Africa)]. After the packhouse treatments were applied, the fruit were separated into replicates and evaluation dates for cold storage $\left(7.5^{\circ} \mathrm{C}\right.$ for 14 weeks). Six evaluation dates were used $(4,6,8$, 
10,12 , and 14 weeks) and at each evaluation date, eight replicates consisting of 25 fruit were evaluated for incidence of rind breakdown for each of the two treatments (inside and outside).

To quantify the canopy light profile, measurements were taken during 2005 in the top $(20 \mathrm{~cm}$ into the leaf canopy from the first leaves), middle ( $1.5 \mathrm{~m}$ from ground level), and below the leaf canopy $(0.5 \mathrm{~m}$ from ground level) of 10 trees. The measurements were done between 1000 and $1200 \mathrm{HR}$ on a clear day using a light meter (LI-250; LI-COR, Lincoln, NE) with a quantum meter (LI-190SA; LI-COR), which took point measurements integrated over $15 \mathrm{~s}$. The $80-\mathrm{cm}-$ long probe, consisting of 80 individual light meters, was divided into four zones, starting at the first leaf $(0$ to $20 \mathrm{~cm})$ and ending closest to the tree trunk $(60$ to $80 \mathrm{~cm})$.

Rind PIGMENT ANALYSIS. Rind pigment analysis has previously been explained in detail (Cronje et al., 2011); briefly, pigments were extracted with ethanol before measuring absorbance at 470, 646, and $664 \mathrm{~nm}$ [Cary 50 conc ultraviolet-visible spectrophotometer; Varian Australia, Mulgrave, Australia]. From the absorbance readings, calculations were made to determine chlorophyll a $\left(\mathrm{C}_{\mathrm{a}}\right)$, chlorophyll $\mathrm{b}\left(\mathrm{C}_{\mathrm{b}}\right)$, total chlorophylls $\left(\mathrm{C}_{\mathrm{a}+\mathrm{b}}\right)$, and total carotenoid $\left(\mathrm{C}_{\mathrm{x}+\mathrm{c}}\right)$ concentrations and were calculated and expressed as milligram per gram dry weight using the Lichtenthaler equations (Lichtenthaler, 1987).

Fruit Photosynthesis. The determination of fruit photosynthesis was conducted during 2007 using eight single-tree replicates. Measurements of net $\mathrm{CO}_{2}$ assimilation rate (A) of attached fruit were made before and after color break, on 18 Mar. and 17 Apr., respectively, using one fruit exposed to the sun for part of the day (outside) and shaded (inside) fruit. The "sun-exposed" fruit were selected for being positioned in the same plane as the outer leaves of the canopy, therefore receiving direct sunlight for the part of the day that photosynthesis measurements were done. These fruit were therefore on the periphery of the leaf canopy toward the outer limit of the 0 - to $20-\mathrm{cm}$ segment as measured by the light meter. The same trees were used for both measurement dates; however, the fruit used were removed at each measurement time to determine fresh weight for calculation of $\mathrm{CO}_{2}$ exchange. The $\mathrm{CO}_{2}$ assimilation rate of attached fruit was determined with a portable photosynthesis system (LI-6400; LI-COR) using a conifer chamber attachment (LI-6400-05; LI-COR). The system is based on the equations derived by Von Caemmerer and Farquhar (1981) to calculate net $\mathrm{CO}_{2}$ assimilation rate, transpiration rate, and stomatal conductance. Because the conifer chamber does not have its own light source, incident light levels (ambient sunlight) were used and photosynthetic photon flux was measured using a quantum sensor (LI-190SA; LI-COR) attached to the conifer chamber. A black photographic cloth was used to block out all light in the chamber to determine dark respiration rate $\left(\mathrm{R}_{\mathrm{d}}\right)$ of the fruit. Cuvette $\mathrm{CO}_{2}$ concentration was controlled at $380 \mu \mathrm{mol} \cdot \mathrm{mol}^{-1}$ using the $\mathrm{CO}_{2}$ injection system (LI-6400-01; LI-COR) and compressed $\mathrm{CO}_{2}$ cylinders. The light-saturated net $\mathrm{CO}_{2}$ assimilation rate $\left(\mathrm{A}_{\max }\right), \mathrm{R}_{\mathrm{d}}$, and light-saturated photosynthetic rate $\left[\mathrm{P}_{\max }\right.$ (the difference between $A_{\max }$ and $R_{d}$ )] are reported.

DETERMINATION OF FLAVEDO CARBOHYDRATE CONCENTRATION. From each positional treatment (inside and outside fruit) and treatment date (January to May), eight replicates $(n=8)$ each consisting of the pooled flavedo of 25 fruit were used for carbohydrate extraction and analyses in all seasons. Only one extraction was performed per replicate. Sugars were extracted and purified from the flavedo by a modification of the method used by Koch and Avigne (1990) and adapted and explained in detail in Cronje et al. (2011). This method, using a solution of methanol, chloroform, and water, was necessary to eliminate the numerous pigments and lipids in the flavedo. An additional step of filtering the extract through a C18 column

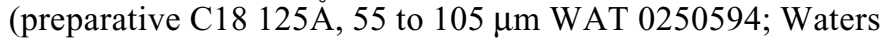
Corp., Milford, MA) was deemed necessary to remove phenolic compounds extracted from the flavedo and to extend the life of the high-performance liquid chromatography (HPLC) column. Carbohydrate analysis was performed using HPLC (1100 Series; Agilent, Waldbronn, Germany) with an autosampler (110 Series; Hewlett-Packard, Waldbronn, Germany) operated by ChemStation software [LC Rev.A.06.03 (509); HewlettPackard]. A ion exchange (stainless steel) column for analysis of sugars and organic acids $(3000 \times 7.8 \mathrm{~mm}$; Model ICSep ICE-99-9850; Transgenomic, Omaha, NE) was used with a guard column (Model ICSep-ICE-GC-801; Transgenomic) and was maintained at $30{ }^{\circ} \mathrm{C}$. Sugars were separated using $17 \mathrm{~mm}$ $\mathrm{H}_{2} \mathrm{SO}_{4}$ at a flow rate of $0.5 \mathrm{~mL} \cdot \mathrm{min}^{-1}$. A refractive index detector (Model G1352A; Agilent) was used to detect the separated sugars. An injection volume of $30 \mu \mathrm{L}$ was used per sample. The sugar concentration of the freeze-dried flavedo was expressed as milligrams per gram dry weight.

Statistical analysis. Differences in rind color, fruit size, and carbohydrate concentration (sucrose, fructose, and glucose) were analyzed using PROC GLM (SAS Version 6.12; SAS Institute, Cary, NC). The significance of treatments was determined from the analysis of variance (ANOVA) and means were separated by least significant difference (LSD). Fruit photosynthesis data were analyzed using a one-way ANOVA to test the significance $(P \leq 0.05)$ of canopy position. A multiple comparison test (Fisher's protected LSD at $P \leq 0.05$ ) was also performed to separate means.

\section{Results}

Fruit deVelopment (Weight, Rind COLOR, AND PIGMents) AND PAR LEVELs. Fruit position within the canopy significantly influenced fruit growth, rind color development, and pigment concentration in the same manner in all seasons, hence only 2005 data are shown to avoid repetition. Inside fruit consistently weighed less than outside fruit (Fig. 1A). The canopy positional effect also resulted in a difference in rind color development of the flavedo (Fig. 1D-F). During the green, immature stage (January to March/April), the inside fruit had a paler but more intense green color (higher chroma values) compared with the outside fruit. After color break (between March and April), the outside fruit developed a more intense orange color (lower hue angle and higher chroma) compared with the more yellow-colored inside fruit at harvest in May. Before color break (March to April), the outside fruit had not only higher levels of chlorophyll (Fig. 1C) but also carotenoids (Fig. 1B) in the flavedo. After color break, the outside fruit had significantly higher levels of carotenoids, which would explain the lower hue angle, whereas chlorophyll concentration did not differ between treatments at harvest in May.

The available light in a 'Nules Clementine' mandarin tree decreases after the first 0 to $20 \mathrm{~cm}$ into the canopy, illustrating that the dense leafy canopy of the citrus tree only allows low levels of $P A R$ to penetrate the inner canopy (Table 1), as 

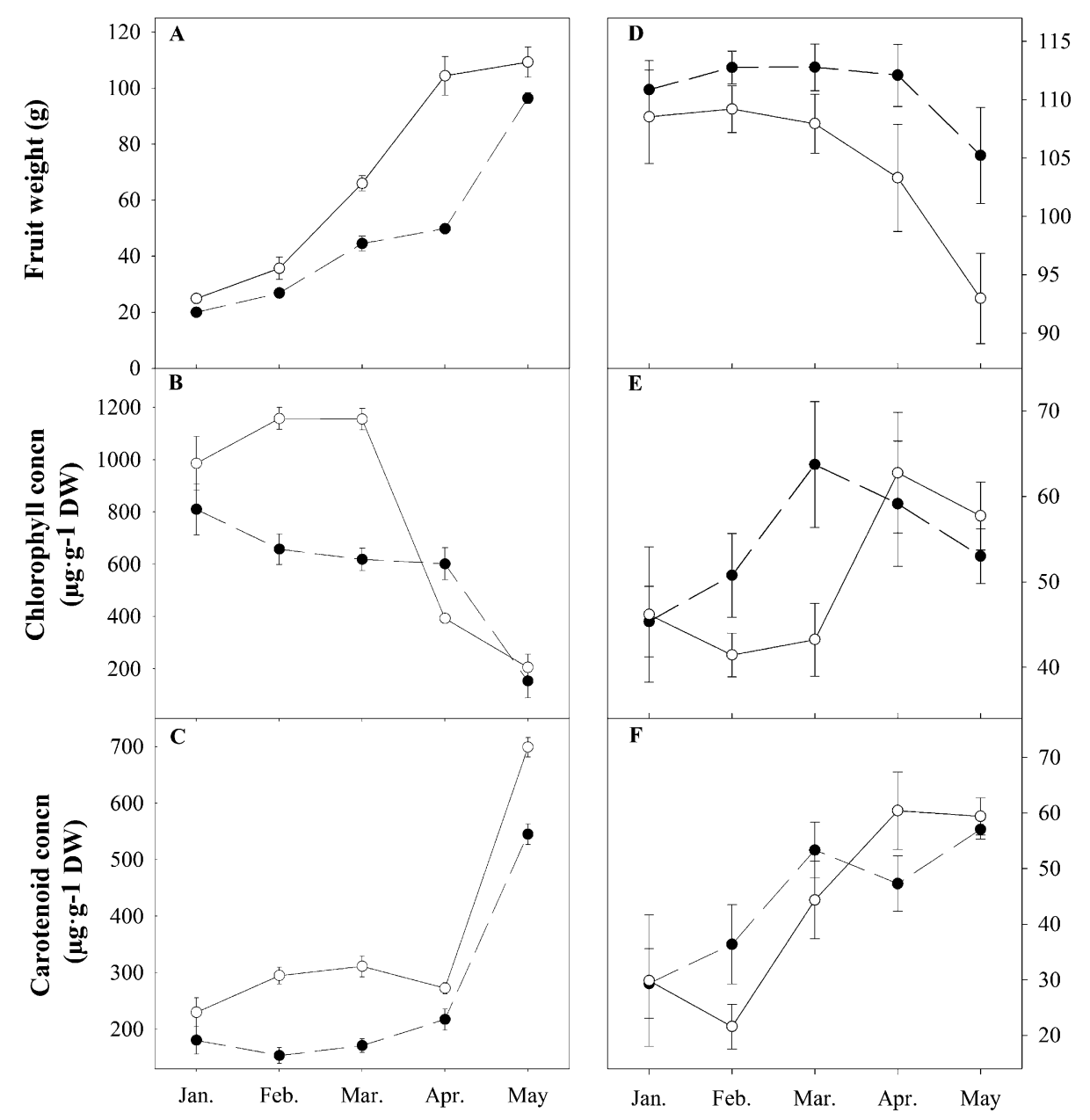

Fig. 1. Pre-harvest changes in fruit weight (A), fruit rind pigment concentration $(\mathbf{B}-\mathbf{C})$, and rind color (D-F) during Stages II and III of fruit development of 'Nules Clementine' mandarin in 2005. Higher hue angle indicates a more yellow fruit, whereas a lower value indicates a more orange color, and high lightness values indicate a less dark color. Chroma represents the vividness of the color, and therefore a high value represents a more intense color. The broken lines and denote the values for inside fruit $(\mathbf{O})$ and solid lines the outside fruit $(O)$. Values are means of 25 fruit per treatment position in the canopy (inside and outside) of eight replicate trees $(n=8)$, with SE.

reported by Greene and Gerber (1967). It is clear that significant differences exist between the $P A R$ levels of the inside and outside of the canopy and these would influence key plant physiological processes such as photosynthesis and transpiration (Jones, 1983).

Fruit $\mathrm{CO}_{2}$ Fixation. The on-tree fruit photosynthetic measurements recorded during 2 clear days, preand post-color break (March and April, respectively), showed significant differences between the $\mathrm{CO}_{2}$ exchange rates of the fruit borne on the inside (no direct sunlight) and outside (full sunlight during part of day) of the tree's canopy ( $A_{\max }$, $R_{d}$, and $P_{\max }$ in Fig. 2). The $A_{\max }$ of fruit borne on the outer canopy was significantly higher than the inner canopy, whereas the $R_{d}$ of fruit in the outside position was significantly lower in both March and April. The $\mathrm{P}_{\max }$ also differed significantly between canopy positions with outside fruit having a much higher $\mathrm{CO}_{2}$ fixation rate. The $\mathrm{A}_{\max }$ and $R_{d}$ values became less negative, whereas $\mathrm{P}_{\text {max }}$ decreased from March to April, coinciding with the rind color break and reduction in chlorophyll concentration in the flavedo (Fig. 2).

Flavedo CARBOHYDRATE CONCentration. Carbohydrate concentration (sucrose, glucose, and fructose) increased in the flavedo during Stages II and III of fruit development in all three seasons

Table 1. Light distribution in the canopy of a 'Nules Clementine' mandarin tree on a clear day. ${ }^{z}$

\begin{tabular}{lcccc}
\hline \multirow{2}{*}{$\begin{array}{l}\text { Section of } \\
\text { canopy }(\mathrm{cm})\end{array}$} & Unit & $\begin{array}{c}\text { Top of } \\
\text { canopy }\end{array}$ & $\begin{array}{c}\text { Middle of } \\
\text { canopy }\end{array}$ & $\begin{array}{c}\text { Bottom of } \\
\text { canopy }\end{array}$ \\
\hline $0-20$ & $\%$ & 28 & 22 & 7 \\
& $\mu \mathrm{mol} \cdot \mathrm{m}^{-2} \cdot \mathrm{s}^{-1}$ & 481 & 359 & 103 \\
$20-40$ & $\%$ & 15 & 6 & 3 \\
& $\mu \mathrm{mol} \cdot \mathrm{m}^{-2} \cdot \mathrm{s}^{-1}$ & 262 & 99 & 42 \\
$40-60$ & $\%$ & 12 & 3 & 2 \\
& $\mu \mathrm{mol} \cdot \mathrm{m}^{-2} \cdot \mathrm{s}^{-1}$ & 203 & 42 & 36 \\
$60-80$ & $\%$ & 12 & 9 & 1 \\
& $\mu \mathrm{mol} \cdot \mathrm{m}^{-2} \cdot \mathrm{s}^{-1}$ & 198 & 140 & 21 \\
\hline
\end{tabular}

${ }^{z}$ The values are the average of measurements in 10 trees. Data are expressed as $P A R$ and $P A R$ percentage relative to full sunlight at each section of the canopy. Measurements were taken from the top of the canopy ( $20 \mathrm{~cm}$ into the top leaves canopy) as well as in the middle of the canopy ( $1.5 \mathrm{~m}$ from ground level) and below the lowest leaves $(0.5 \mathrm{~m}$ from ground). The measurements are divided into four sections starting at the first leaves on the outside of the canopy $(0$ to $20 \mathrm{~cm})$ until $80 \mathrm{~cm}$ into the canopy.

$P A R=$ photosynthetically active radiation.
(Fig. 3). Sucrose concentration was higher at the start of the sampling period than that of glucose and fructose with the glucose and fructose concentrations noticeably increasing during the last month of fruit development. Sucrose concentration (on average) reached $\pm 4 \mathrm{mg} \cdot \mathrm{g}^{-1}$ between February and March, whereas the two reducing sugars only attained that level between April and May (close to harvest), coinciding with a marked color change of the flavedo (Fig. 1).

Fruit position, and therefore exposure to high (outside) or low (inside) light levels in the canopy, could be an important factor that affects the flavedo concentration of all three sugars during fruit development. In 2004 and 2005, the flavedo from fruit borne on the outside of the canopy had significantly higher sucrose, glucose, and fructose concentrations than the fruit borne inside the canopy. However, sucrose, glucose, and fructose concentrations during 2007 did not differ significantly, although the mean values were generally higher in the flavedo from the outside.

Rind BREAKDOWN INCIDENCE DURING COLD STORAGE. The incidence of rind breakdown increased during all seasons along a progressive pattern (Fig. 4). Canopy position during fruit development (inner and outer canopy) influenced the 


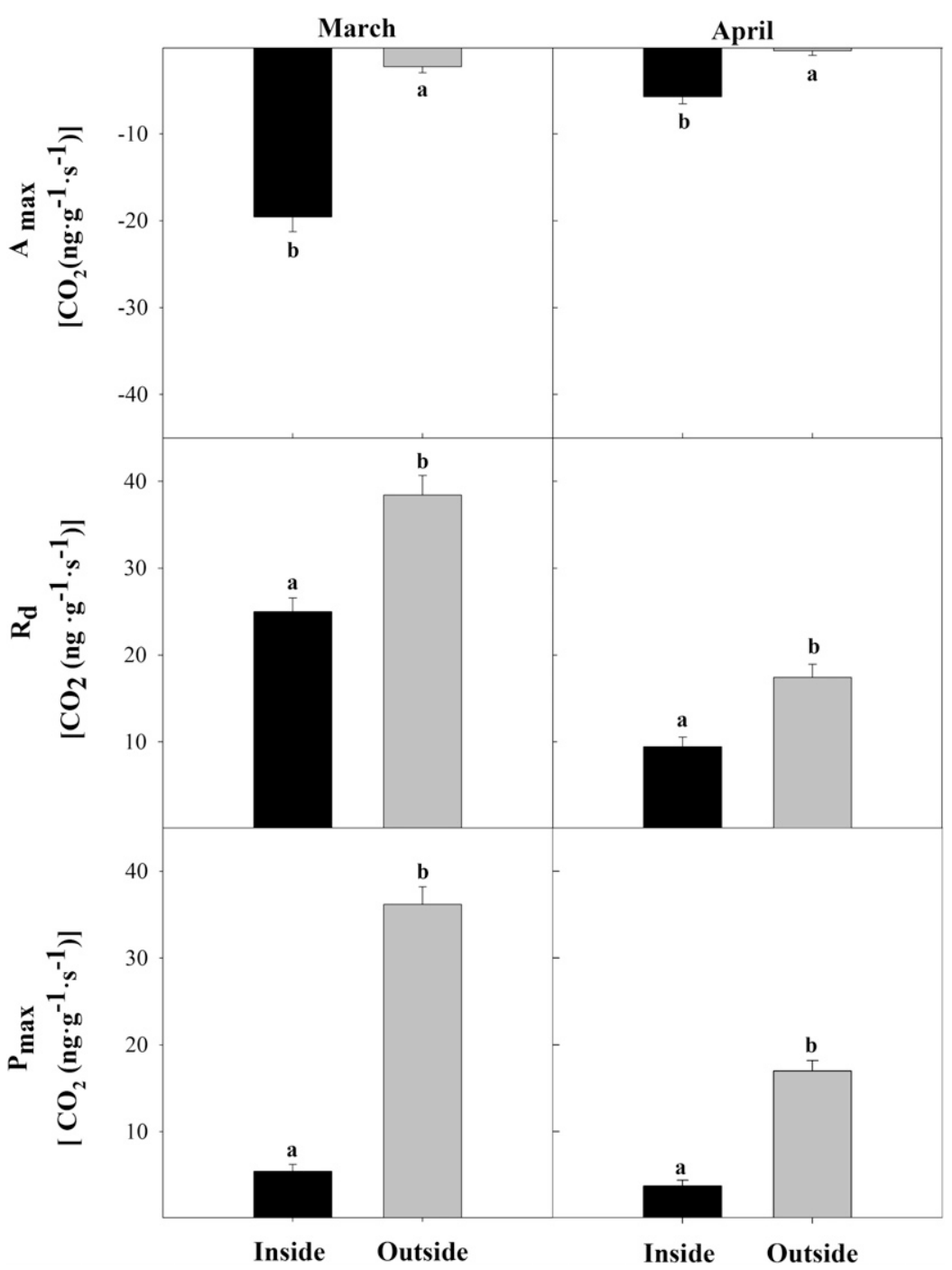

Fig. 2. Light-saturated net $\mathrm{CO}_{2}$ assimilation rate $\left(\mathrm{A}_{\max }\right)$, dark respiration rate $\left(\mathrm{R}_{\mathrm{d}}\right)$, and light-saturated photosynthetic rate $\left[\mathrm{P}_{\max }\left(\right.\right.$ the difference between $\mathrm{A}_{\max }$ and $\left.\mathrm{R}_{\mathrm{d}}\right)$ ] of 'Nules Clementine' mandarin fruit measured before (March) and after (April) rind color break. Values of $\mathrm{CO}_{2}$ exchange were expressed on a fresh weight basis. Values are means of eight measurements per treatment $(n=8)$. Different lettering on bars indicates significant differences according to Fisher's least significant difference test at $P \leq 0.05$.

rind condition and resulted in a higher incidence of rind breakdown of the inside fruit compared with the outside fruit in all seasons.

\section{Discussion}

None of the data presented in this study can be discussed in isolation because the interdependence of the carbohydrate accumulating process is well established in plant physiology. It is proposed that the variation in PAR levels in the citrus canopy could result in a cascade effect in the fruit rind; first, influencing chlorophyll concentration followed by the photosynthetic rate and finally carbon fixation. In addition, it can be inferred that if this process does not function optimally, a reduction in the physiological condition of the rind could develop resulting in the higher incidence of rind breakdown.

The impact of the dense citrus leaf canopy is evident in the reduction in $P A R$ levels from the outer to the inner parts of the canopy. In addition, outside fruit rind pigment composition (chlorophyll and carotenoid) resulted in a "greener" rind color before and a more intense orange after color break. The lower $P A R$ levels consequently could effect the reduction in fruit photosynthesis before and after color break (during which a significant reduction in chlorophyll content occurs). The outside fruit not only have a higher photosynthetic rate, but also a higher respiration rate, and therefore the outside fruit are synthesizing and metabolizing carbohydrates at a high rate compared with the inside fruit. Carbohydrate concentrations (reducing and non-reducing sugars) in the flavedo increased during both Stages II and III of fruit development. This finding agrees with previous reports in the literature of not only increased carbohydrate concentration, but also increased carbohydrate metabolism until fruit maturity (Holland et al., 1999; Komatsu et al., 1999, 2002).

The color change of the flavedo from green to orange is an important quality trait of the citrus fruit rind, and adequate sugar accumulation in the flavedo is necessary to supply energy required for the chloroplastto-chromoplast conversion (Huff, 1984). The reduction in chlorophyll concentration between March and April resulted in an unmasking effect of the carotenoids and is the main reason for the change in hue angle. However, the dramatic color change between April and May, as expressed by hue angle, would largely be the result of the sudden increase in carotenoid pigments. In addition to the higher market value of well-colored citrus fruit, carotenoids play an essential role in scavenging reactive oxygen species and at relatively low concentrations are effective in protecting membrane lipids from oxidation (Allan and Fluhr, 2007; Larson, 1988). As a result of their exclusion from adequate sunlight during their development, fruit borne inside the canopy therefore had poorer rind color, lower chlorophyll and carotenoid contents and, therefore, lower carbohydrate levels. During fruit development, the sucrose concentration in the flavedo increases as a result of three processes, viz. photosynthesis in the flavedo, sucrose influx from the leaves, and the cycling transformation of sucrose and hexose sugars in the cell (Huber, 1989). It is known that accumulated carbohydrates perform the function of stored energy reserves and are part of the structural framework of cells during development (Dennis and Blakeley, 2000; Kays and Paull, 2004). The higher hue angle value (yellower) of the inside fruit flavedo could therefore be construed as a visual symptom, indicative of a reduced rind condition, which could be a contributing factor to the higher incidence of rind breakdown.

In contrast to these results, Purvis (1980) found no difference in total or non-reducing sugar concentration of grapefruit rind between the interior and exterior positions in the canopy. However, inside grapefruit were less susceptible to CI than 


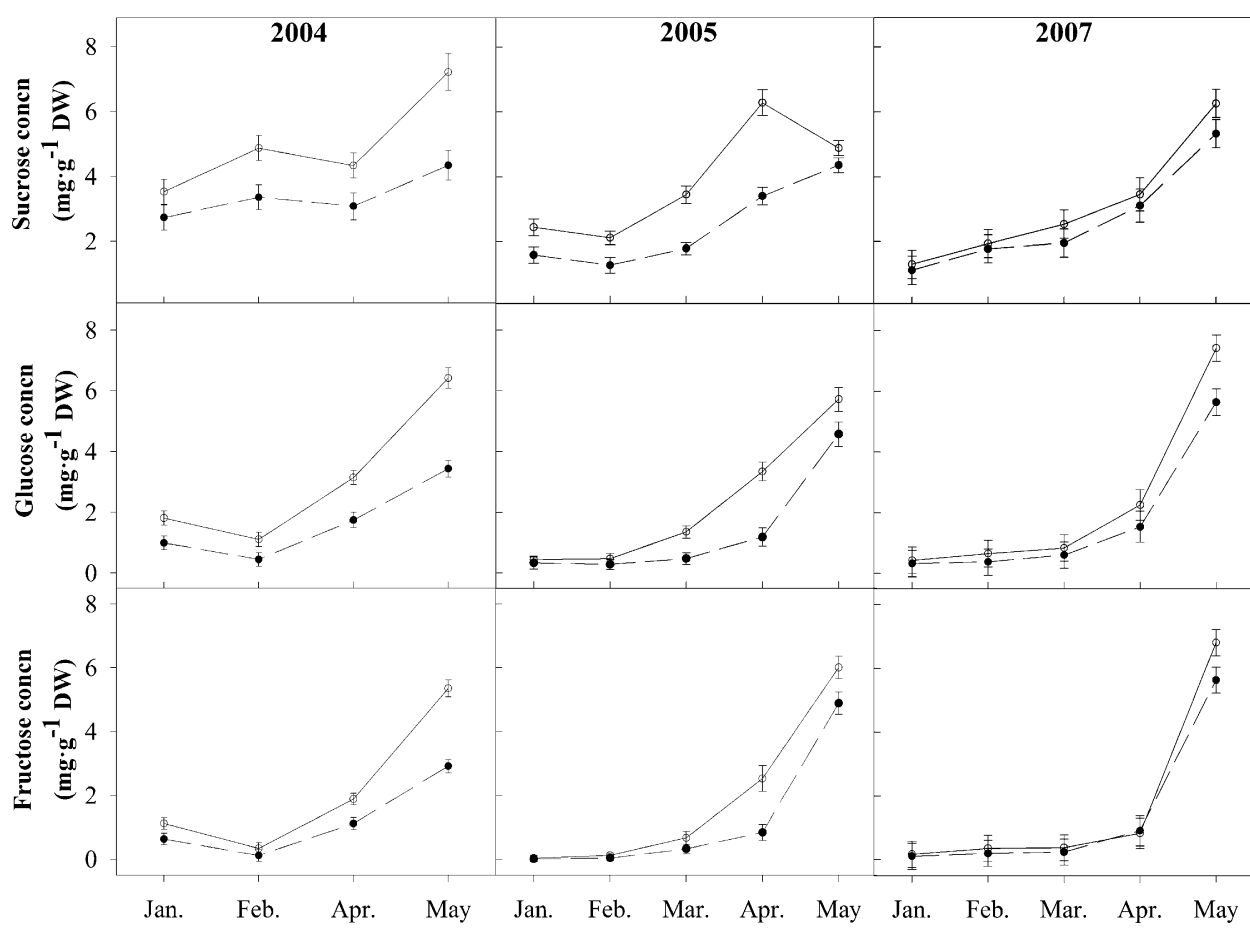

Fig. 3. The accumulation in the flavedo of sucrose, glucose, and fructose during Stages II and III of 'Nules Clementine' mandarin fruit development in 2004, 2005, and 2007. Values are means $(\mathrm{n}=8)$ with SE bars. Values for the inside fruit ( $)$ flavedo are denoted by broken lines, whereas those for outside fruit $(\bigcirc)$ flavedo are solid lines.

sun-exposed fruit. A possible explanation could be the different bearing habits of grapefruit and mandarins. Mandarin fruit, in a well-managed tree, are in general more exposed to sunlight than grapefruit, which hang primarily within the leafy canopy out of direct sunlight. Insufficient carbohydrate concentration not only results in lower internal fruit quality, but could be involved in increased susceptibility to CI of the rind (Holland et al., 2002; Purvis and Grierson, 1982; Purvis and Rice, 1983). Furthermore, levels of carbohydrates alone were argued not to be solely responsible for the canopy positional effect on fruit susceptibility to CI (Purvis, 1980, 1989; Purvis and Rice, 1983). Rind breakdown is not related to low cold storage temperature with higher incidence at 7.5 than $-0.5{ }^{\circ} \mathrm{C}$ (Cronje et al., 2011). The causal mechanism of these two disorders could be different; however, carbohydrate content of the rind could contribute to the general rind condition and the susceptibility to both of these physiological disorders.

The results from the on-tree fruit photosynthetic measurements concur with a previous study (Moreshet and Green, 1980), which indicates a citrus fruit exposed to adequate $P A R$ could accumulate $\mathrm{CO}_{2}$ to enable it to develop the rind to a certain extent independently of the leaf photosynthesis. This higher $\mathrm{CO}_{2}$ fixation rate of the outside fruit offers support to the notion that adequately exposed fruit have the ability to synthesize carbohydrates necessary for flavedo development and thereby possibly contributing to a reduction in the sensitivity to physiological rind breakdown. However, it should be noted that the inside fruit, as opposed to outside fruit, were not exposed to the same high light during measurements, and it could be argued that they may have the ability to fix $\mathrm{CO}_{2}$ at the same rate if exposed to similar levels of PAR. On the other hand, the inside fruit were constantly exposed to low light conditions during development and therefore lack the chlorophyll concentration vital for fruit photosynthesis to provide adequate $\mathrm{CO}_{2}$ fixation for optimal flavedo development (Moreshet and Green, 1980).

The reduced photosynthesis after color break would largely be the result of the reduction in chlorophyll concentration in the flavedo during this developmental stage (Ikoma et al., 2001) and is in accordance with the literature (Bean et al., 1963; Moreshet and Green, 1980). The reduction of the chlorophyll concentration coincides not only with the color change in the rind (April to May) and the reduction of $\mathrm{P}_{\max }$, but also the increase of reducing (sucrose) and non-reducing (glucose and fructose) carbohydrate concentrations. The increase is, therefore, not limited to only glucose and fructose concentrations (which would originate from sucrose), but includes sucrose, possibly being imported from the leaves as fruit photosynthesis decreases at this stage. This argument concurs with Chen et al. $(2004,2008)$ who reported fruit photosynthesis of fully mature 'Satsuma' mandarin fruit to approach zero and that at this stage, the rind becomes the major sink of leaf photosynthates. The reduction in sucrose phosphate synthase activity in the late stage of 'Fortune' mandarin fruit rind development also indicates that the maintained sucrose levels in the flavedo are probably the result of the importation from leaves and not synthesis of sucrose in the rind (Holland et al., 1999). The period when differences in carbohydrate levels increase between inside and outside fruit (after color break, April to March) coincides with the lower chlorophyll levels and could indicate the importance of carbohydrates supplied from the leaves to the rind at this stage.

The reduction in respiration rate from March to April (before and after color break, respectively) in both inside and outside fruit is normal in citrus fruit as they progress toward maturity (Bain, 1958; Todd et al., 1961). The flavedo is known to respire at twice the rate of the albedo and three times the rate of the pulp (Hussein, 1944). The higher respiration rate of the outside fruit could, therefore, be an indication of higher fruit pulp and rind growth rates (metabolic activity) resulting in not only increased fruit size, but also possibly a better developed rind structure of outside fruit. However, the flavedo is thought to be able to refix $30 \%$ to $100 \%$ of the $\mathrm{CO}_{2}$ produced by fruit respiration (Huang et al., 1992). The reduction in respiration rate from March to April and the increase in sucrose, glucose, and fructose concentrations could indicate that a pool of hexose is synthesized and stored at this stage without being used in respiration and could then serve as a respiratory substrate for subsequent use during postharvest storage. A lack of adequate concentrations of carbohydrates in the flavedo could therefore possibly reduce the physiological condition of the rind during fruit development as well as postharvest storage. 


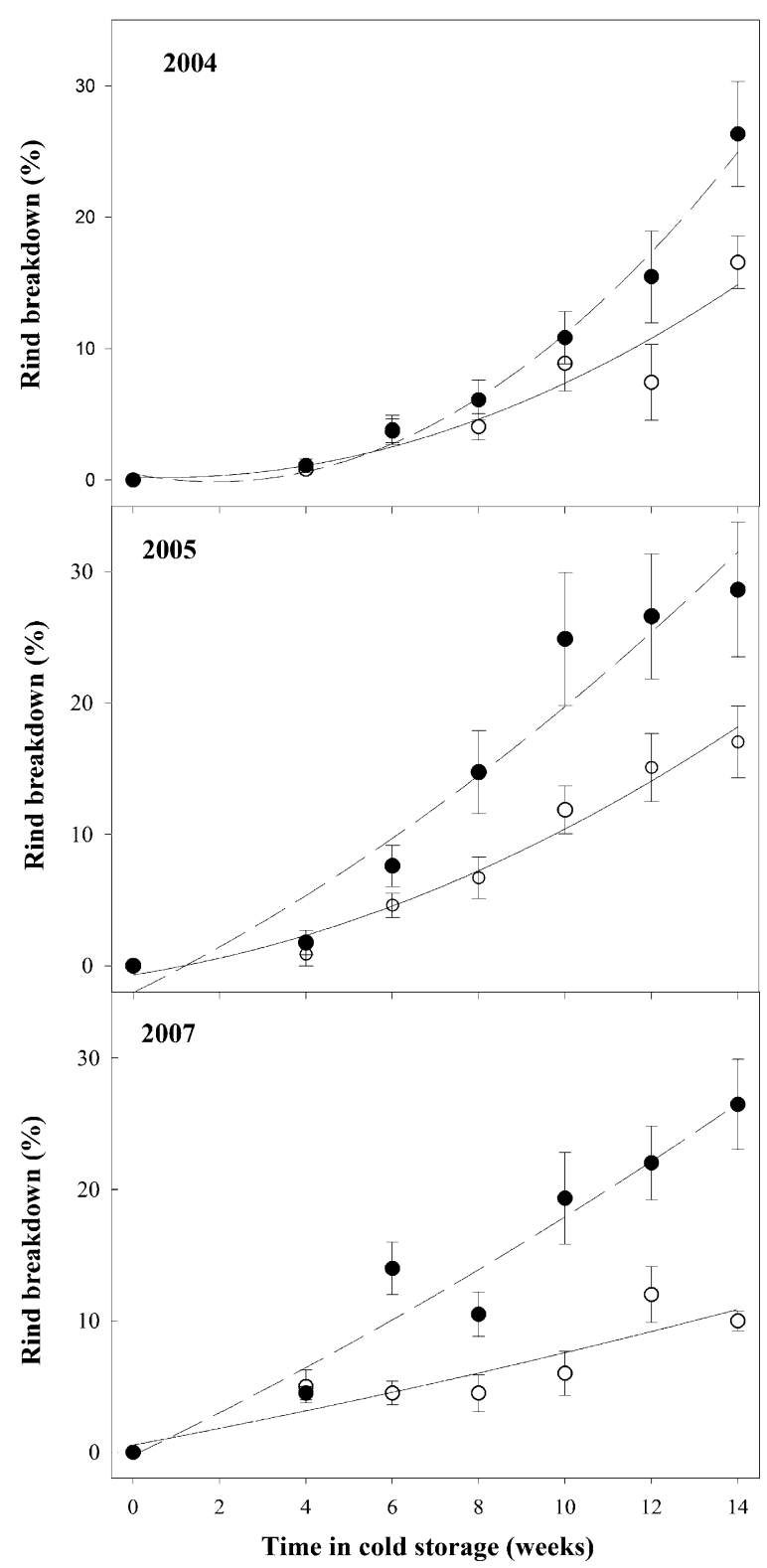

Fig. 4. Percentage rind breakdown incidence of 'Nules Clementine' mandarin harvested in May and stored at $7.5^{\circ} \mathrm{C}$ during 2004, 2005, and 2007. Values for the inside fruit $(\boldsymbol{O})$ are denoted by broken lines, whereas those for outside fruit $(\bigcirc)$ are solid lines. A quadratic polynomial line was fitted to the data resulting in the following $R^{2}$ values: 2004 inside $=0.95,2004$ outside $=0.93,2005$ inside $=0.9$, 2005 outside $=0.96,2007$ inside $=0.91,2007$ outside $=0.72$. Values are means $(\mathrm{n}=8)$ with sE bars. of the inside fruit flavedo is also suspected to contribute to poorer rind condition, which could lead to higher susceptibility to the physiological disorder, rind breakdown.

\section{Literature Cited}

Allan, A.C. and R. Fluhr. 2007. Ozone and reactive oxygen species, p. 1229-1304. In: Roberts, K. (ed.). Handbook of plant science. Vol. 2. Wiley, Hoboken, NJ.

Aschan, J.L. and H. Pfanz. 2003. Non-foliar photosynthesis-A strategy of additional carbon acquisition. Flora 198:81-97.

Bain, J.M. 1958. Morphological, anatomical and physiological changes in the developing fruit of Valencia orange Citrus sinensis (L.). Osbeck. Austral. J. Bot. 6:1-24.

Barry, G.H., W.S. Castle, and F.S. Davies. 2000. Juice quality of 'Valencia' sweet orange among citrus-producing regions in Florida and between canopy positions. Proc. Intl. Soc. Citricult. Congr. 1:308-314.

Barry, G.H. and S. le Roux. 2010. Preharvest foliar sprays of prohexadione-calcium, a gibberellin biosynthesis inhibitor, induce chlorophyll degradation and carotenoid synthesis in citrus rind. HortScience 45:242-247.

Bean, R.C., G.G. Porter, and B.K. Barr. 1963. Photosynthesis and respiration in developing fruits. II. Variations in photosynthetic capacities during colour change in citrus. Plant Physiol. 38:285-290.

Bean, R.C. and G.W. Todd. 1960. Photosynthesis and respiration in developing fruits. I. ${ }^{14} \mathrm{CO}_{2}$ uptake by young oranges in light and in dark. Plant Physiol. 35:425-429.

Blanke, M.M. 1996. Stomata, transpiration and photosynthesis of Citrus orange fruit. Proc. Intl. Citricult. 2:1017-1020.

Blanke, M.M. and F. Lenz. 1989. Fruit photosynthesis-A review. Plant Cell Environ. 12:31-46.

Chen, J.W., S.L. Zhang, M. Xie, H.X. Xu, and J.G. $\mathrm{Xu}$. 2004. Fruit photosynthesis and assimilate translocation and partitioning: Their characteristics and role in sugar accumulation in developing Citrus unshiu fruit. Acta Bot. Sin. 44:158-163.

Chen, J.W., S.L. Zhang, M. Xie, H.X. Xu, and J.G. $\mathrm{Xu}$. 2008. Fruit shading changed photosynthate partitioning, sugar and accumulation in developing Satsuma mandarin (Citrus unshiu Marc) fruit. Proc. Intl. Soc. Citricult. Congr. 1:520-527.

To conclude, the concentration of the three sugars measured (sucrose, glucose, and fructose) in the flavedo increased during Stages II and III of fruit development. However, glucose and fructose concentrations lagged behind sucrose concentration and only increased 1 month before harvest. The flavedo sampled from the inside and outside of the canopy (low and higher sun exposure, respectively) contained different levels of these reducing and non-reducing sugars with the inside flavedo possessing, in total, a lower sugar concentration. Photosynthesis measurements of inside and outside fruit showed the outside fruit could possibly have a positive carbon budget, which could supply carbohydrates to the flavedo cell structure during fruit development before color break as a result of an influx of carbohydrates from the leaves. The lower carbohydrate concentration
Cronje, P.J.R. 2007. Postharvest rind disorders of citrus fruit. Citrus Research International, Nelspruit, South Africa.

Cronje, P.J.R., G.H. Barry, and M. Huysamer. 2011. Postharvest rind breakdown of 'Nules Clementine' mandarin is influenced by ethylene application, storage temperature and storage duration. Postharvest Biol. Technol. 60:192-201.

Dennis, D.T. and S.D. Blakeley. 2000. Carbohydrate metabolism, p. 621-675. In: Buchanan, B., W. Gruissem, and R. Jones (eds.). Biochemistry and molecular biology of plants. Amer. Soc. Plant Physiol., Rockville, MD.

El-Otmani, M., A. Ait-Oubahou, and L. Zacarías. 2011. Citrus sp.: Orange, mandarin, tangerine, clementine, grapefruit, pomelo, lemon and lime, p. 467-474. In: Yahia, E.M. (ed.). Postharvest biology and technology of tropical and subtropical fruits. Woodhead Publishing, Cambridge, UK. 
Goldschmidt, E.E. and K.E. Koch. 1996. Citrus, p. 797-823. In: Zamski, E. and A.A. Schaffer (eds.). Photoassimilate distribution in plants and crops: Source-sink relationships. Marcel Dekker, New York, NY.

Greene, B.A. and J.F. Gerber. 1967. Radiant energy distribution in Citrus trees. J. Amer. Soc. Hort. Sci. 90:77-85.

Holland, N., H.C. Menezes, and M.T. Lafuente. 2002. Carbohydrates as related to the heat-induced chilling tolerance and respiratory rate of 'Fortune' mandarin fruit harvested at different maturity stages. Postharvest Biol. Technol. 25:181-191.

Holland, N., J.M. Sala, H.C. Menezes, and M.T. Lafuente. 1999. Carbohydrate concentration and metabolism as related to maturity and chilling sensitivity of cv. Fortune mandarins. J. Agr. Food Chem. 47:2513-2518.

Huang, T.-B., R.L. Darnell, and K.E. Koch. 1992. Water and carbon budgets of developing citrus fruit. J. Amer. Soc. Hort. Sci. 117:287293.

Huber, S.C. 1989. Biochemical mechanism for regulation of sucrose accumulation in leaves during photosynthesis. Plant Physiol. 91:656-662.

Huff, A. 1984. Sugar regulation of plastid interconversions in epicarp of citrus fruit. Plant Physiol. 76:307-312.

Hussein, A.A. 1944. Respiration in the orange. A study of systems responsible for oxygen uptake. J. Biol. Chem. 155:201-211.

Ikoma, Y., A. Komatsu, M. Kita, K. Ogawa, M. Omura, M. Yano, and T. Moriguchi. 2001. Expression of a phytoene synthase gene and characteristic carotenoid accumulation during citrus fruit development. Physiol. Plant. 111:232-238.

Jones, H.G. 1983. Plants and microclimate: A quantitative approach to environmental plant physiology. Cambridge Univ. Press, Cambridge, UK.

Kays, S.J. and R.E. Paull. 2004. Postharvest biology. Exon Press, Athens, GA.

Koch, K. 1984. The path of photosynthates translocation into citrus fruit. Plant Cell Environ. 7:647-653.

Koch, K.E. and W.T. Avigne. 1990. Post-phloem, non-vascular transfer in citrus. Kinetics, metabolism, and sugar gradients. Plant Physiol. 93:1405-1416.

Komatsu, A., T. Moriguchi, K. Koyama, M. Omura, and T. Akihama. 1999. Deferential expression of three sucrose-phosphate synthase isoforms during sucrose accumulation in citrus fruit (Citrus unshiu Marc.). Plant Sci. 42:169-178.

Komatsu, A., T. Moriguchi, K. Koyama, M. Omura, and T. Akihama. 2002. Analysis of sucrose synthase genes in citrus suggests different roles and phylogenetic relationships. J. Expt. Bot. 53:61-71.

Larson, R.A. 1988. The antioxidants of higher plants. Phytochemistry 27:969-978.

Lichtenthaler, H.K. 1987. Chlorophylls and carotenoids: Pigments of photosynthetic biomembranes. Methods Enzymol. 146:350-382.
Morales, P., F.S. Davies, and R. Littell. 2000. Pruning and skirting affect canopy microclimate, yields, and fruit quality of Orlando tangelo. HortScience 35:30-35.

Moreshet, S. and G.C. Green. 1980. Photosynthesis and diffusion conductance of the Valencia orange fruit under field conditions. J. Expt. Bot. 31:15-27.

Purvis, A.C. 1980. Influence of canopy depth on susceptibility of 'Marsh' grapefruit to chilling injury. HortScience 15:731-733.

Purvis, A.C. 1989. Soluble sugar and respiration of flavedo tissue of grapefruit stored at low temperature. HortScience 24:320-322.

Purvis, A.C. and W. Grierson. 1982. Accumulation of reducing sugar and resistance of grapefruit peel to chilling injury as related to winter temperatures. J. Amer. Soc. Hort. Sci. 107:139-142.

Purvis, A.C. and J.D. Rice. 1983. Low-temperature induction of invertase activity in grapefruit flavedo tissue. Phytochemistry 22: 831-834.

Purvis, A.C. and G. Yelenosky. 1983. Translocation of carbohydrates and proline in young grapefruit trees at low temperatures. Plant Physiol. 73:877-880.

Reitz, H.J. and J.W. Sites. 1948. Relationship between position on the tree and analysis of citrus fruit with special reference to sampling and meeting internal grades. Proc. Florida State Hort. Soc. 54:80-90.

Sites, J.W. and H.J. Reitz. 1949. The variation in individual Valencia oranges from different locations of tree as a guide to sampling methods and spot picking for quality. Part I. Soluble solids in the juice. Proc. Amer. Soc. Hort. Sci. 54:1-9.

Syvertsen, J.P. and J.J. Lloyd. 1994. Citrus, p. 65-99. In: Schaffer, B. and P.C. Andersen (eds.). Handbook of environmental physiology of fruit crops, subtropical and tropical crops, Vol. II. CRC Press, Boca Raton, FL.

Tadeo, J.L., J.M. Optiz, and A. Estelles. 1987. Sugar changes in Clementine and orange fruit during ripening. J. Hort. Sci. 62:531537.

Todd, G.W., R.C. Bean, and B. Propst. 1961. Photosynthesis and respiration in developing fruits. II. Comparative rates at various stages of development. Plant Physiol. 36:69-73.

Turrell, F.M. and L.J. Klotz. 1940. Density of stomata and oil glands and incidence of waterspot in the rind of Washington Navel oranges. Bot. Gaz. 101:861-871.

Von Caemmerer, S. and G.D. Farquhar. 1981. Some relationships between the biochemistry of photosynthesis and the gas exchanges of leaves. Planta 153:376-387.

Vu, J.C.V., G. Yelenosky, and M.G. Bausher. 1985. Photosynthetic activity in flower buds of 'Valencia' orange [Citrus sinensis (L.) Osbeck]. Plant Physiol. 78:420-423.

Yen, C.R. and K.E. Koch. 1990. Developmental changes in translocation and localization of ${ }^{14} \mathrm{C}$-labeled assimilates in grapefruit: Light and dark $\mathrm{CO}_{2}$ fixation by leaves and fruit. J. Amer. Soc. Hort. Sci. 115:815-819. 